\title{
Teachers' Perceptions Regarding Factors Affecting Concept Based Learning at Government Schools in Nowshera, Pakistan
}

\author{
Ihsan Ullah \\ Elementary \& Secondary Education Department, Khyber Pakhtunkhwa, Pakistan \\ Email address: \\ ihsanullah82@yahoo.com \\ To cite this article: \\ Ihsan Ullah. Teachers' Perceptions Regarding Factors Affecting Concept Based Learning at Government Schools in Nowshera, Pakistan. \\ Humanities and Social Sciences. Vol. 9, No. 5, 2021, pp. 202-207. doi: 10.11648/j.hss.20210905.18
}

Received: July 1, 2021; Accepted: August 4, 2021; Published: October 15, 2021

\begin{abstract}
Education plays a pivotal role in the development of a country. Here the author did focus on the best teaching methodologies and skills that is concept based teaching so that the student learn conceptually. There should be critical thinking and problem solving skills developed in the students. The main objective of the research study is to explore the perceptions of secondary school teachers regarding factors affecting concept based learning at government secondary schools in district Nowshera. The population of the study is all secondary school teachers at government high schools in district Nowshera. The sample size was 105 secondary school teachers. The primary data was collected through questionnaire. The questionnaire was personally distributed among the teachers and got excellent response from them. The major findings showed the effectiveness of concept based learning and major factors that affecting concept based learning. In light of the said findings, certain major recommendations were made in order to achieve the maximum benefits of the study as secondary school teachers may be encouraged and motivated towards concept based learning techniques. Government school teachers may be given more skills and techniques of teaching and learning through effective in-service training and refresher courses. This study however, successfully plays a very important role in highlighting of the effectiveness of concept based learning and the factors that affecting concept based learning at government secondary schools for boys in district Nowshera. There may be core skills incorporated in the curriculum so that the students may be equipped with the twenty first century skills i.e critical thinking and problem solving, communication and collaboration, creativity and imagination, citizenship, digital literacy and students' leadership.
\end{abstract}

Keywords: Teachers' Perceptions, Factors, Concept Based Learning, Secondary School Teacher

\section{Introduction}

Concept based learning is the modern technique for students by which the students learn the basic concepts of the terms. It is against the traditional technique i.e. rote learning or rote memorization. Unfortunately, in Pakistani government schools, the students learn mostly through rote learning or rote memorization, which is not effective and beneficial for students. But in the modern world specially advanced and developed countries, students learn through a modern and effective technique i.e. concept based learning. Educationists and research scholars suggest that modern techniques of education are superior to traditional techniques of teaching and learning. Concept-Based Learning provides students with the opportunity to gain theory, content knowledge and comprehension in a more authentic way. Concept based learning is the modern technique which enables the students to learn effectively [1]. In addition, this approach helps students develop advanced cognitive abilities such as critical thinking, problem solving, and communication skills [2].

Traditional teaching and learning methods do not seem to be able to create the employee businesses look for today. It may be that there are other approaches to learning that would have greater success. Discovery learning seems to be a promising approach for a number of reasons. Discovery learning is an approach to learning that can be facilitated by particular teaching methods and guided learning strategies [3]. David and France [4] stated that without feedback no 
student can solve his/ her problems. If students do not know about the basic concepts, they cannot write any creative writing etc. They also pointed out that modern techniques of learning may be adapted and used in all secondary schools in the United States of America so that the students learn quickly and easily.

Concept-based learning is a modern technique of learning, is used in the advanced developed and countries. A majority of educationists and scholars prefer concept-based learning over rote learning. Concept based learning is the most useable technique of learning. All the developed and advanced communities and societies adapt this technique. The concept based learning gives outstanding results and it develops creative power of the students. Traditional teaching hampers the concept based learning and it is considered one of the drawbacks of traditional teaching. It mostly promotes rote memorization among the students.

\subsection{Significance of the Study}

Very less number of research studies has been carried out in respect of the proposed area of study in Pakistan. It is actually, imperative to undertake a descriptive study to explore the teachers' perceptions regarding adaptation of concept based learning at secondary schools in district Nowshera. It is hoped that the outcome of the study would be useful for teachers, scholars, policy makers, and planners. This aspect would certainly enable them to reframe their thinking and enlightened policies. The study would allow secondary school teachers to put efforts for significance improvement in adapting concept based learning technique for students. The study would describe the effectiveness of concept based learning and weaknesses of rote learning. The researcher's findings, conclusions, recommendations and suggestions would be very beneficial for the educationists, scholars, teachers, and students etc.

\subsection{Objectives of the Study}

1) To find out the factors affecting concept based learning;

2) To discern the effectiveness of concept based learning;

3) To explore the teachers' perceptions regarding adaptation of concept based learning;

4) To identify the weaknesses of rote learning.

\subsection{Research Questions}

1) What are the factors affecting concept based learning?

2) Is concept based learning an effective technique of learning?

3) Is concept based learning technique better than rote learning?

4) What are the teachers' perceptions regarding adaptation of concept based learning?

5) What are the weaknesses of rote learning?

\subsection{Hypotheses of the Study}

1) $\mathrm{H}_{1}$ : The concept based learning is an effective technique for students.
2) $\mathrm{H}_{0}$ : The concept based learning is not an effective technique for students.

\section{Literature Review}

According to Michal [5] in short time and competitive exams rote learning is a good instrument but by this way the students only can get marks not conceptual learning. Rote learning is for time being while concept based learning is for a long time moreover, rote learning technique has less creativity while conceptual learning technique enables a student for critical thinking and creative writing. If the students just memorize the facts and don't know the basic concepts, it is not fruitful for the students in future exams and professional screening tests.

Lan, and Ian [6] described similar writing actions are serious apparatuses of many writing examination tasks, including information regaining, writing organization, and paper federation. Conventional procedures are hard they approximate the surface join between papers built on the arguments they indicated and disregard profounder meaningful connections. They projected a new degree who judges likeness at together the spoken and meaningful stages, and learns from social choices how to chain them by using technology learning methods. Experiments showed that the new degree formed values for papers that were more consistent with people's decisions than people were with each other. They also used it to categorize and collection large paper sets covering dissimilar kinds and topics, and found that it improved both organization and get-together papers.

Barbara [7] pointed out that instruction for philosophical knowledge needs instructors to recognize the maximum central foundations in their sequence, and to plan and grow planed actions that will empower pupils to deal totally with these basic perceptions or services external of period. The perceptions are additional protected with in period or operational actions concerning energetic knowledge and pupil- pupil communications. Projects and actions for bottomless knowledge can be designed in plentiful methods within corrections, delivered that the four serious foundations of profound knowledge.

Cohen [8] said that of course, most constructivist instructors would argue that actual life simulations, on the job training, and project-based learning are more active at learning new concepts than rote memorization moreover, untrained or incompetent teacher may one of the major cause of rote learning and stresses on the activity based learning. One of the major drawbacks of rote learning was less creativity.

According to Novak [9], the complete past of investigation and exercise that leads towards progress and advancement of education. Founded on Ausubel's adaptation philosophy of significant education and practical theory of knowledge, the philosophy comprises five elements: educator, student, theme material, background, and appraisal, separately of each surely combined usefully to result great heights of significant 
education. The expansion and use of perception planning to enable significant knowledge is debated and a perfect for education is existing that shapes upon the philosophy and connected performs.

According to Anne [10], rote learning is simply the storage of data in the brain. It does not require any understanding of the data being stored. Rote memorization can be a useful tool, but real, meaningful learning comes from the mastery of key concepts. Here he pointed out that by rote learning the students only learn the facts for the time being and forget these facts after some time while concept based learning technique keeps the facts for long time. Rote memorization needs more force and patience to the students and wasted energy while concept based learning needs little energy to learn. Moreover, concept based learning is an effective technique of learning and it is far better than the traditional technique of learning.

Johnson [11] stated that rote learning is the factual environment of repetition, though, the said criteria is not only for teachers but students as well. And it is the accountability of educators to impart pupils how to use it to help them in their instructive occupation. It is true that information without understanding is of slight use, but understanding necessitates information and it takes time and energy to obtain. According to Bloom Classification knowledge and comprehension are the most important steps of cognitive development therefore, for comprehension skills concept based learning is better than rote memorization.

Langer [12] said that memorizing is an approach for attending in substantial that has no private sense. The students used different items and papers to pass the exams, but whenever they use these different items and papers they fail in the test or examinations. This drawback of rote memorization is applicable to most of the students and teachers in different places and things like in the memorizing of textbook for school, in technical material in the office, or in any additional material. Many years the disadvantages of rote memorization had discovered.

\section{Methodology}

The study was descriptive in nature and quantitative method was used. The population of the study included all secondary school teachers in Nowshera city, Khyber Pakhtunkhwa. The sample included 105 secondary school teachers by using Likert's five point scale. The primary data were collected from teachers while secondary data were collected from office record, documents and review of literature.

\subsection{Data Collection}

The study used quantitative technique of research. The researcher visited all the schools personally and administered all the questionnaires among respondents.

\subsection{Data Analysis}

The data obtained were tabulated and analyzed by using statistical technique such as mean score. On the basis of analysis and interpretation of data, conclusions were drawn and recommendations were made.

\section{Results and Discussions}

Table 1. Sum of Square of the responses of 105 Secondary School Teachers.

\begin{tabular}{|c|c|c|c|c|c|c|c|c|}
\hline S. No. & Statements & SA & $\mathbf{A}$ & $\mathbf{N}$ & DA & SD & MEAN & $\begin{array}{l}\text { STANDARD } \\
\text { DEVIATION }\end{array}$ \\
\hline 1 & Traditional curriculum is one of the factors that affect concept based learning. & 32 & 65 & 4 & 3 & 1 & 1.877 & 0.758 \\
\hline 2 & Untrained teacher is one of the factors that affect concept based learning. & 28 & 55 & 4 & 9 & 9 & 2.137 & 0.45 \\
\hline 3 & Slow learner student is one of the factors that affect concept based learning. & 13 & 42 & 14 & 30 & 6 & 2.22 & 0.28 \\
\hline 4 & Course completion tension is one of factor that affects concept based learning. & 24 & 37 & 11 & 31 & 3 & 2.184 & 0.44 \\
\hline 5 & Overcrowded class is one of the factors that affect concept based learning. & 32 & 41 & 7 & 12 & 13 & 2.226 & 0.34 \\
\hline 6 & Traditional teaching is a big flaw in our education system. & 49 & 38 & 9 & 4 & 5 & 2.1 & 0.24 \\
\hline 8 & Rote learning may be replaced by concept based learning. & 57 & 31 & 7 & 8 & 2 & 2.056 & 0.24 \\
\hline 9 & Present examination system discourages concept based learning. & 37 & 41 & 12 & 10 & 5 & 2.18 & 0.39 \\
\hline 10 & Concept based learning technique is not effective for arts subjects. & 9 & 11 & 23 & 42 & 20 & 2.25 & 0.25 \\
\hline 11 & $\begin{array}{l}\text { Concept based learning plays a concrete role in the development of students' } \\
\text { intellectual abilities. }\end{array}$ & 51 & 43 & 10 & 6 & 5 & 1.75 & 1.086 \\
\hline 12 & Papers and tests may be based on concept based learning like EATA, NTS and other tests. & 32 & 65 & 4 & 3 & 1 & 1.877 & 0.758 \\
\hline 13 & Teaching in the class with different activities is better than traditional way of teaching. & 29 & 33 & 15 & 13 & 15 & 2.32 & 0.32 \\
\hline 15 & The duration of Matric program may be increased up to three years. & 42 & 31 & 12 & 7 & 3 & 2.25 & 0.66 \\
\hline 16 & The curriculum and textbooks may be based on concept based learning. & 37 & 36 & 12 & 11 & 9 & 2.23 & 0.28 \\
\hline 17 & Some teachers are not willing to adapt concept based learning. & 34 & 41 & 19 & 7 & 4 & 2.17 & 0.433 \\
\hline 18 & Teacher training is important for teachers to know more techniques of teaching. & 43 & 51 & 8 & 3 & 4 & 2.0 & 0.60 \\
\hline 19 & Concept Based Learning may be adapted at all government schools. & 57 & 31 & 7 & 8 & 2 & 2.056 & 0.24 \\
\hline 20 & Concept Based Learning needs more energy and time for learning. & 42 & 31 & 12 & 7 & 3 & 2.25 & 0.66 \\
\hline
\end{tabular}

Table 1 shows the total responses of 105 respondents. 
Sum of Square of Table 1.

Table 2. Calculations and responses of Secondary school Teachers.

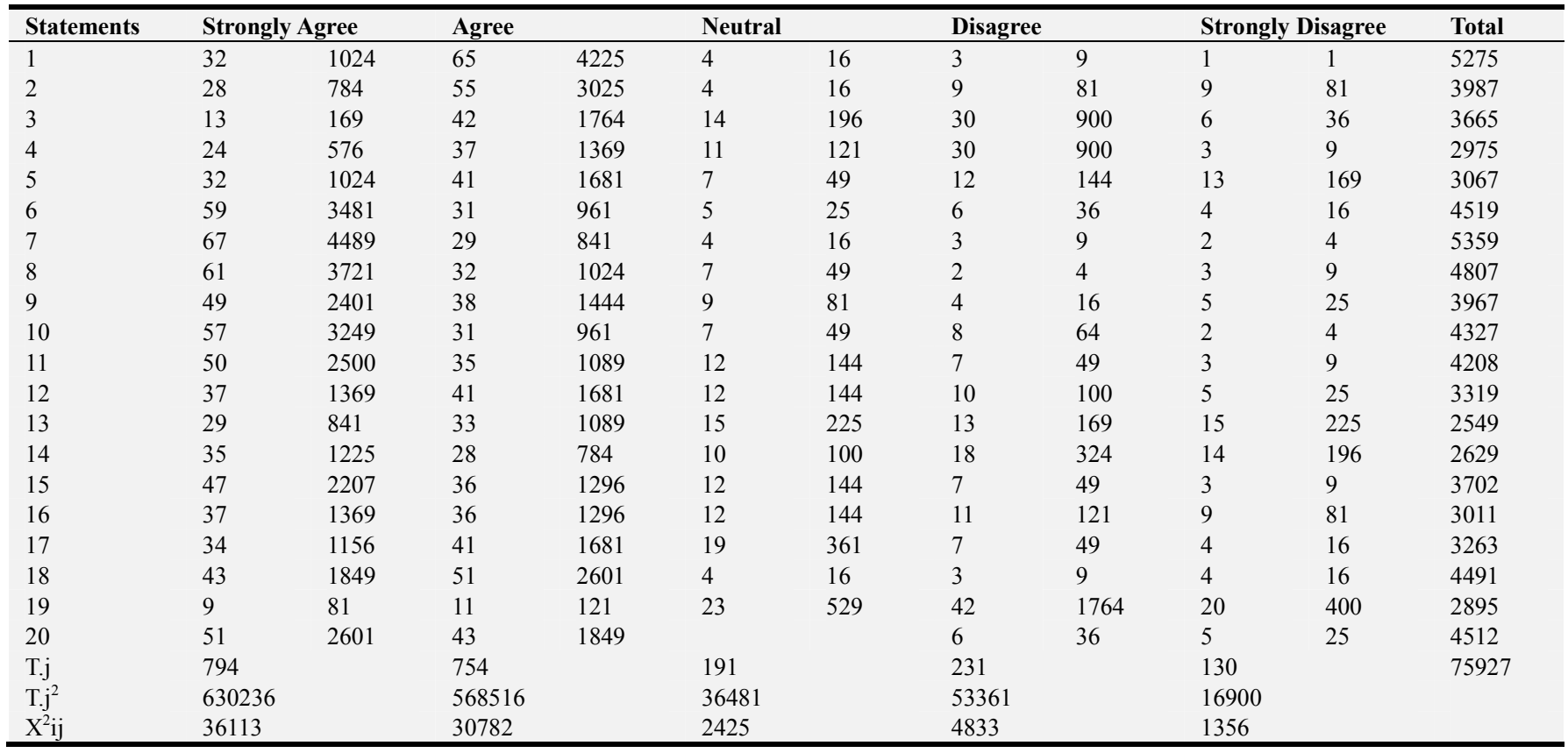

Table 2 depicts the calculations and squares of 105 responses. All the data is combined for using F-Test with ANOVA table. F-Test

As the null hypothesis of the study is that the concept based learning is not an effective technique for students so;

Level of significance $\alpha=0.05$

Test statistic to be used is

$$
\begin{gathered}
\mathrm{F}=\frac{\mathrm{S}^{2} \mathrm{~b}}{\mathrm{~S}^{2} \mathrm{w}} \\
\text { Correction Factor }=\frac{\mathrm{T}^{2}}{\mathrm{n}}=\frac{(2100)^{2}}{100}=\frac{4410000}{100}=44100
\end{gathered}
$$

$$
\begin{aligned}
& \mathrm{SST}=\sum \mathrm{X}^{2} \mathrm{i}-\mathrm{C} . \mathrm{F} \\
& \mathrm{SST}=75927-44100=31827 \\
& \mathrm{SSB}=\sum \mathrm{T}^{2} . \mathrm{j}-\mathrm{C} . \mathrm{F} \\
& \mathrm{SSB}=65284.7-44100=21184.7 \\
& \mathrm{SSW}=\mathrm{SST}-\mathrm{SSB} \\
& \mathrm{SSW}=31827-21184.7=10642.3
\end{aligned}
$$

Table 3 shows the ANOVA table with sources of variation, degree of freedom, sum of square, mean of square and F-test. The calculated value is 7.46 while the tabulated value is 3.06 so it is cleared from the following given formula.

Table 3. ANOVA table with sources of variation.

\begin{tabular}{lllll}
\hline Sources of variation & Degree of freedom & Sum of Square & Mean of square & F \\
\hline Between & $\mathrm{k}-1=5-1=4$ & 21184.7 & 5296.175 & 7.46 \\
Within & $\mathrm{n}-\mathrm{k}=20-5=15$ & 10642.3 & 709.48 & \\
\hline
\end{tabular}

$$
\text { Critical region is } \mathrm{F} \geq \mathrm{F} 0.05(4,15)=3.06
$$

Since the computed value of $\mathrm{F}=7.46$ falls in the critical region so, it rejected $\mathrm{H}_{0}$ and concluded that the concept based learning is an effective technique for students.

Table 4. Chi Square test of Goodness.

\begin{tabular}{lllll}
\hline Observed frequencies & Expected Frequencies & & & \\
\hline Oi & Ei & Oi-Ei & $(\mathbf{O i}-\mathbf{E i})^{\mathbf{2}}$ & $(\mathbf{O i - E i})^{\mathbf{2}} / \mathbf{E i}$ \\
\hline 794 & 756.19 & 37.81 & 1429.59 & 1.89 \\
754 & 718.7 & 35.3 & 1246.09 & 0.73 \\
191 & 181.90 & 9.1 & 82.91 & 0.55 \\
231 & 220 & 11 & 121 & 0.310 \\
130 & 123.80 & 6.2 & 38.44 & 4.93 \\
\hline
\end{tabular}




\subsection{Chi Square Test of Goodness}

Table 4 shows the Chi Square Fit Test of Goodness to know the reliability of F-Test in ANOVA. The calculated value is shown through the following statistical formula.

$$
\mathrm{X}^{2} \geq \mathrm{X}^{2}{ }_{0.05}(4)=7.82
$$

Since the calculated value of $\mathrm{X}^{2}$ does not fall in the critical region so, it rejected the null hypothesis and concluded that F-Test is reliable and valid for using this data.

Table 5. Logarithm Transformation.

\begin{tabular}{|c|c|c|c|c|c|c|c|}
\hline Statements & Strongly Agree & Agree & Neutral & Disagree & Strongly Disagree & MEAN & STANDARD DEVIATION \\
\hline 1 & $2.5(6.25)$ & $2.81(7.89)$ & $1.60(2.56)$ & $1.477(2.18)$ & $1(1)$ & 1.877 & 0.758 \\
\hline 2 & $2.447(5.98)$ & $2.74(7.50)$ & $1.60(2.56)$ & $1.95(3.80)$ & $1.95(3.80)$ & 2.137 & 0.45 \\
\hline 3 & $2.113(4.46)$ & $2.62(6.88)$ & $2.14(4.57)$ & $2.47(6.10)$ & $1.77(3.13)$ & 2.22 & 0.28 \\
\hline 4 & $2.38(5.66)$ & $2.56(6.55)$ & $2.04(4.16)$ & $2.47(6.10)$ & $1.47(2.16)$ & 2.184 & 0.44 \\
\hline 5 & $2.50(6.25)$ & $2.61(6.81)$ & $1.84(3.38)$ & $2.07(4.28)$ & $2.11(4.45)$ & 2.226 & 0.34 \\
\hline 6 & $2.77(7.67)$ & $2.49(6.20)$ & $1.69(2.85)$ & $1.77(3.13)$ & $1.60(2.56)$ & 2.064 & 0.52 \\
\hline 7 & $2.82(7.95)$ & $2.46(6.05)$ & $1.60(2.56)$ & $1.47(2.18)$ & $1.30(1.69)$ & 1.93 & 0.45 \\
\hline 9 & $2.69(7.23)$ & $2.57(6.60)$ & $1.95(3.80)$ & $1.60(2.56)$ & $1.69(2.85)$ & 2.1 & 0.24 \\
\hline 10 & $2.75(7.56)$ & $2.49(6.20)$ & $1.84(3.38)$ & $1.90(1.30)$ & $1.30(1.69)$ & 2.056 & 0.24 \\
\hline 11 & $2.69(7.23)$ & $2.51(6.30)$ & $2.079(4.32)$ & $1.84(3.38)$ & $1.47(2.16)$ & 2.11 & 0.5 \\
\hline 12 & $2.56(6.55)$ & $2.61(6.81)$ & $2.079(4.32)$ & $2.00(4.0)$ & $1.69(2.85)$ & 2.18 & 0.39 \\
\hline 13 & $2.46(6.05)$ & $2.51(6.30)$ & $2.17(4.70)$ & $2.11(4.45)$ & $2.17(4.70)$ & 2.32 & 0.32 \\
\hline 14 & $2.54(6.45)$ & $2.44(5.95)$ & $2.0(4.0)$ & $2.25(5.66)$ & $2.14(4.57)$ & 2.27 & 0.52 \\
\hline 15 & $2.67(7.12)$ & $2.55(6.50)$ & $2.079(4.32)$ & $1.84(3.38)$ & $1.47(2.16)$ & 2.25 & 0.66 \\
\hline 18 & $2.63(6.91)$ & $2.70(7.29)$ & $1.60(2.56)$ & $1.47(2.16)$ & $1.60(2.56)$ & 2.0 & 0.60 \\
\hline 19 & $1.95(3.80)$ & $2.04(4.16)$ & $2.36(5.56)$ & $2.62(6.86)$ & $2.30(5.29)$ & 2.25 & 0.25 \\
\hline 20 & $2.70(7.29)$ & $2.63(6.91)$ & $0(0)$ & $1.77(3.13)$ & $1.69(2.85)$ & 1.75 & 1.086 \\
\hline T.j & 51.04 & 51.0 & 36.85 & 38.25 & 33.74 & & \\
\hline$T^{2} \cdot \mathrm{j}$ & 2605.08 & 2601.0 & 1358.36 & 1463.69 & 1138.38 & & 210 \\
\hline$\sum X^{2} i j$ & 139.08 & 130.45 & 72.45 & 75.61 & 58.99 & & 468.58 \\
\hline
\end{tabular}

\subsection{Logarithm Transformation}

Table 5 shows all the data with complete squares for logarithm transformation. This formula shows the homogeneity among the values and data.

Correction factor $($ C.F $)=\mathrm{T}^{2} / \mathrm{n}=(210.88)^{2} / 100$

$$
\begin{aligned}
& =444470.37=444.70 \\
& \text { Total SS }=\sum \sum \mathrm{X} 2 \mathrm{i} . \mathrm{j}-\mathrm{C} . \mathrm{F}
\end{aligned}
$$

$$
\begin{aligned}
\text { Between SS } & =\sum \mathrm{T}^{2} . \mathrm{j} / \mathrm{r}-\mathrm{C} . \mathrm{F} \\
& =9166.41 / 20-444.70 \\
& =458.41-444.70 \\
& =13.62
\end{aligned}
$$

Within SS $=$ TSS - BSS

$$
=23.88-13.62=10.26
$$

Table 6. Analysis of Variance.

\begin{tabular}{llll}
\hline S. O. V & d.f & Sum of Squares & Mean Squares \\
\hline Between SS & $\mathrm{K}-1=5-1=4$ & 23.88 & $13.88 / 4$ \\
Within SS & $\mathrm{n}-\mathrm{k}=20-5=15$ & 10.26 & $10.26 / 15$ \\
\hline
\end{tabular}

Table 6 shows the analysis of variance for the data given in logarithmic transformation. And calculated value falls in critical region so; it rejected the null hypothesis and concluded that the data is normal and homogeneous.

\section{Conclusion}

The study concluded that all the secondary school teachers of government high schools for boys in district Nowshera showed same perceptions regarding adaptation of concept based learning. The teachers highlighted about the factors that affect concept based learning and main drawbacks of rote learning. The study also showed the effectiveness of concept based learning. No teacher wants to adapt rote learning technique but due to some tough and non-conducive environment of the government schools they are not able to adapt this technique. Moreover, the teachers stressed on activity based learning and they gave positive response to concept based learning. The study gave a clear idea about the adaptation of concept based learning at government secondary schools in district Nowshera. Teacher of every randomly selected school wished that the government should adapt conceptual learning techniques in the curriculum and textbooks. They also pointed out that the duration of Matric may be increased up to three years. They told about some basic problems of teaching which are faced by the secondary school teachers in government high schools in district Nowshera. The researcher's findings, conclusions, recommendation and suggestions will be very beneficial 
for the educationists, scholars, teachers, and students etc. The study clearly differentiated the two techniques of learning and told the merits and demerits of both the techniques of learning.

\section{Recommendations}

The following recommendations were made:

i. Curriculum and textbooks may be designed on the basis of concept based learning.

ii. The Curriculum may have to be updated and it has to be related to a lot of practical work in case of all subjects at this stage, so that the classroom teaching becomes more meaningful and interesting.

iii. The duration of Matric program may be increased up to three years.

iv. The matriculation stage may prepare the students for skilled jobs; say with a year additional course in the selected field.

v. Examination system may be improved and cleared from all unfear means.

vi. The government school teachers may be trained frequently, in-service training and refresher courses may be given to all teachers.

vii. The teacher may encourage the students towards activity and concept based learning.

viii. The rote learning may be eliminated from government schools and concept based learning may be completely adapted.

ix. The government may provide more space, classrooms and teaching staff at overcrowded schools.

x. The teacher may teach with different activities and keep the students busy during teaching.

xi. Six core skills may be adapted in the curriculum for the development of critical thinking and creativity of the students.

\section{References}

[1] Andrew, A. L. (2010). "Concept-based Learning: General Tips to Parents" a research article on Washington.

[2] Barbara J. M. (2010). 'Promoting Deep Learning' the University of Texas at San Antonio.

[3] Castronova, A. J. (2011). "Discovery learning for the $21 \mathrm{st}$ Century: What is it and how does it compare to traditional learning in effectiveness in the 21st Century?" a research article university of United States.

[4] Cohen, A. (2011). "why rote memorization is more important that you think" a research article in Ireland.

[5] Etienne, R. \& W. (1999). "learning is as much a part of our human nature as eating or sleeping" a research article London.

[6] Floor M. \& Nil, P. B. (2001). 'Comparing the effectiveness of rote and meaningful instruction and Exercises for learning topographical facts' Master's Thesis, Faculty of Social Sciences, University of Utrecht.

[7] Gove, M. (2012). "Tough exams and learning by rote are the keys to success" a research article Washington.

[8] Hadjerrouit, B. \& Wan. T. (2003). 'Teaching and Learning School Informatics: A Concept-Based Pedagogical Approach' Faculty of Technology and Sciences, University of Agder Serviceboks, Kristiansand, Norway.

[9] Johnson, B. (2010). "when rote learning makes sense" a research article in London.

[10] Morse, David. and Jutras, France. (2008), "Implementing Concept-based Learning in a Large Undergraduate Classroom" a combine research article in France.

[11] Ramya, L. \& I. M. (Dec 11, 2012). 'Rote learning an evil in education system' national survey reveals Chennai, India.

[12] Jane, N.. (2011). 'A Rational Analysis of Rule-based Concept Learning' a research article University of California, Berkeley.

[13] Zachry, L. (2010). "Rote Memorization versus Mastery of Concepts" Ph.D. Thesis University in Australia. 